\title{
High Aedes spp. larval indices in Kinshasa, Democratic Republic of Congo
}

Francis Wat'senga Tezzo', Sylvie Fasine1, Emile Manzambi Zola', Maria del Carmen Marquetti², Guillaume Binene Mbuka', Gillon Ilombe', Richard Mundeke Takasongo', Nathalie Smitz , Juan Andre Bisset ${ }^{2}$, Wim Van Bortel ${ }^{4,5}$ and Veerle Vanlerberghe ${ }^{6^{*}}$ (1)

\begin{abstract}
Background: Dengue, yellow fever, chikungunya and Zika are among the most important emerging infectious vector-borne diseases worldwide. In the Democratic Republic of Congo (DRC), increases in cases of dengue and outbreaks of yellow fever and chikungunya have been reported since 2010. The main vectors of these arboviruses, Aedes aegypti and Aedes albopictus, have been reported in DRC, but there is a lack of detailed information on their presence and spread to guide disease control efforts.
\end{abstract}

Methods: In 2018, two cross-sectional surveys were conducted in Kinshasa province (DRC), one in the rainy (January/February) and one in the dry season (July). Four hundred houses were visited in each of the four selected communes (N'Djili, Mont Ngafula, Lingwala and Kalamu). Within the peri-domestic area of each household, searches were conducted for larval habitats, which were then surveyed for the presence of Aedes larvae and pupae. A subset of the immature specimens were reared to adults for morphological identification followed by DNA barcoding of the specimens to validate identifications.

Results: The most rural commune (Mont Ngafula) had the highest pupal index (number of Aedes spp. pupae per 100 inspected houses) at 246 (20) pupae/100 houses, and Breteau index (Bl; number of containers positive for immature stages of Aedes spp. per 100 households) at 82.2 (19.5) positive containers/100 houses for the rainy (and dry) season, respectively. The BI was 21.5 (4.7), 36.7 (9.8) and 41.7 (7.5) in Kalamu, Lingwala and N'Djili in the rainy (and dry) season, respectively. The house index (number of houses positive for at least one container with immature stages of Aedes spp. per 100 inspected houses) was, on average, across all communes, 27.5\% (7.6\%); and the container index (number of containers positive for immature stages of Aedes spp. per 100 inspected containers) was $15.0 \%$ (10.0\%) for the rainy (and dry) season, respectively. The vast majority of Aedes-positive containers were found outside the houses [adjusted odds ratio 27.4 (95\% confidence interval 14.9-50.1)]. During the dry season, the most productive containers were the ones used for water storage, whereas in the rainy season rubbish and tires constituted key habitats. Both Ae. aegypti and Ae. albopictus were found. Anopheles larvae were found in different types of Aedes larval habitats, especially during the rainy season.

Conclusions: In both surveys and in all communes, the larval indices (BI) were higher than the arbovirus transmission threshold values established by the World Health Organization. Management strategies for controlling Aedes in Kinshasa need to target the key types of containers for Aedes larvae, which are mainly located in outdoor spaces, for larval habitat destruction or reduction.

\footnotetext{
*Correspondence: vvanlerberghe@itg.be

${ }^{6}$ Tropical Infectious Disease Group, Public Health Department, Institute of Tropical Medicine (ITM), Nationalestraat 155, Antwerp, Belgium Full list of author information is available at the end of the article
}

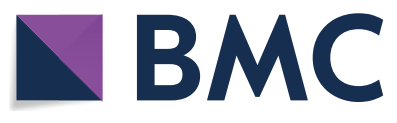

(c) The Author(s) 2021. This article is licensed under a Creative Commons Attribution 4.0 International License, which permits use, sharing, adaptation, distribution and reproduction in any medium or format, as long as you give appropriate credit to the original author(s) and the source, provide a link to the Creative Commons licence, and indicate if changes were made. The images or other third party material in this article are included in the article's Creative Commons licence, unless indicated otherwise in a credit line to the material. If material is not included in the article's Creative Commons licence and your intended use is not permitted by statutory regulation or exceeds the permitted use, you will need to obtain permission directly from the copyright holder. To view a copy of this licence, visit http://creativeco mmons.org/licenses/by/4.0/. The Creative Commons Public Domain Dedication waiver (http://creativecommons.org/publicdomain/ zero/1.0/) applies to the data made available in this article, unless otherwise stated in a credit line to the data. 
Keywords: Kinshasa, Central Africa, Aedes, Survey, Chikungunya, Democratic Republic of Congo

\section{Background}

Arboviruses cause a variety of diseases, such as dengue, yellow fever, chikungunya and Zika, which are among the most important emerging infectious diseases worldwide [1-3]. The distribution of these diseases and their transmitting vectors have been well characterized for Latin America and Southeast Asia [4-6], but our understanding of arbovirus ecology in sub-Saharan Africa remains limited [7-9]. Dengue seroprevalence studies have shown that there is, or has been, dengue virus circulation in Cameroon, demonstrated by $12.5 \%$ immunoglobulin $\mathrm{G}$ (IgG) positivity; in Burkina Faso, demonstrated by $36 \%$ IgG positivity; in Nigeria, demonstrated by $45 \%$ IgG positivity [7]; and in Tanzania, demonstrated by $50.6 \%$ IgG positivity [10]. However, few reports have shown the importance of dengue as a cause of acute fever in these settings. This is also a case for the presence of dengue in the Democratic Republic of Congo (DRC), where the virus was found in stored samples: a dengue antigen test was positive for three suspected chikungunya cases in Kinshasa in 2012 [11]; $0.6 \%$ of dried blood spots taken during a Demographic Health Survey were positive in 2013-2014 [12]; and 3.5\% of suspected cases of yellow fever in the Bas Congo region between 2002 and 2013 were dengue positive [13]. More recently, in 2015-2016, in Mont Ngafula (a suburban area of Kinshasa), 8.1\% of acute fever cases were dengue positive [14], and 30.2\% of the 342 study participants had dengue IgG antibodies. Although no outbreak of dengue has thus far been reported in DRC, in the neighboring country of Angola there was an outbreak of dengue with an estimated attack rate of $10 \%$ in 2013 [15]. By contrast, there have been apparent outbreaks of chikungunya, such as the one in Kenya in 2004 [16], in Tanzania in 2013 [17], in Mozambique in 2018 [18], in Brazzaville (DRC) in 2011 [19] and 2019 [20], and in Kinshasa, capital of DRC in 2000 [21], 2012 [22] and 2019 [23]. Such outbreaks can affect large populations, i.e. $67 \%$ of the population in Kenya [24]. Besides dengue and chikungunya, other alpha-, flaviand bunyaviruses were also found in mosquito samples (Aedes and Culex) in Kinshasa in 2014 [25]. Zika has been rarely detected in sub-Saharan Africa [26], but several yellow fever outbreaks, with the last major one in 2016, have been described [27].

Information on the presence and distribution of Aedes mosquitoes in sub-Saharan Africa is even more difficult to find than information on the pathogens discussed above. This lack of entomological data forces recourse to suitability maps, which are based on mathematical models, to estimate arbovirus transmission risk [28]. However, measures of real Aedes spp. infestation levels would give more reliable insights for both risk and mitigation strategies [29]. Both Aedes aegypti and Aedes albopictus are found in sub-Saharan Africa; Ae. aegypti is native to the region, whereas Ae. albopictus was introduced from Southeast Asia [30] in early 2000 [31], and specifically into Kinshasa (DRC) in 2018 [32]. Both species have been detected in domestic environments [30], such as in Kinshasa, a megacity with a high population density and movement of people, but precise larval indices for Aedes remain unknown. Without knowing the main locations of Aedes larval habitats or the types of containers in which Aedes become adults, it is impossible to define effective larval source management strategies for Kinshasa.

In this study, we evaluate larval indices of Aedes spp. together with the characteristics of their preferred larval habitats, to help produce evidence-based guidance for Aedes control efforts and to provide insight into the potential for the local mosquito population to transmit arboviruses in Kinshasa, the capital of DRC.

\section{Methods \\ Settings}

The surveys took place in Kinshasa, the capital city of DRC, which is located in Central Africa. Kinshasa lies at $279 \mathrm{~m}$ above sea level and is characterized by a tropical climate with a rainy season between October and May, and a dry season from June to September. The average temperature varies between 18 and $32{ }^{\circ} \mathrm{C}$, and the average monthly rainfall varies between 2 and $222 \mathrm{~mm}$, in the dry and rainy seasons, respectively. Kinshasa covers an area of $9965 \mathrm{~km}^{2}$ and has an estimated population of almost 12 million people. The city is administratively subdivided into 24 communes, which are grouped into four districts: Tshangu in the east, Lukunga in the north, Mont Amba in the southeast and Funa in the center west. In this study, four communes were purposively selected to capture diverse ecological, urbanization, and epidemiological conditions (i.e. history of arbovirus outbreaks) and water supply systems (Fig. 1).

N'Djili is a peri-urban commune in the east of the city, within Tshangu district, where many informal economic activities, specifically vehicle repair shops, are located. Urban infrastructure and services, such as waste water infrastructure and garbage collection, are deficient. Almost all (97\%) of the houses have a water supply 
system in their compound, but quality, volume and availability of water are problematic for a high number of them. The population density of this area is estimated at 39,000 people $/ \mathrm{km}^{2}$.

Kalamu II is a commune in the center of town, within Funa district, and is mainly residential. The main economic activity is technical service provision. It has an estimated population density of 47,000 people $/ \mathrm{km}^{2}$.

Mont Ngafula I is situated in the south of the city, bordering Mont Amba district, and is a typical semi-urban area with an estimated population density of 730 people/ $\mathrm{km}^{2}$. It is geographically characterized by hills (and erosion) and small valleys. The main economic activity is agriculture and the selling of agricultural products in Kinshasa city. Mont Ngafula I is emblematic of unplanned urbanization, as it has a deficient water supply system in terms of both the rate of supply (i.e. as low as two times per week) and waste water disposal.

Lingwala is a commune in the center of the city, within Lukunga district, and has a large number of informal street markets. It is a more urbanized area than the others, and has a fairly good water supply. The population density is estimated at 33,000 people $/ \mathrm{km}^{2}$.

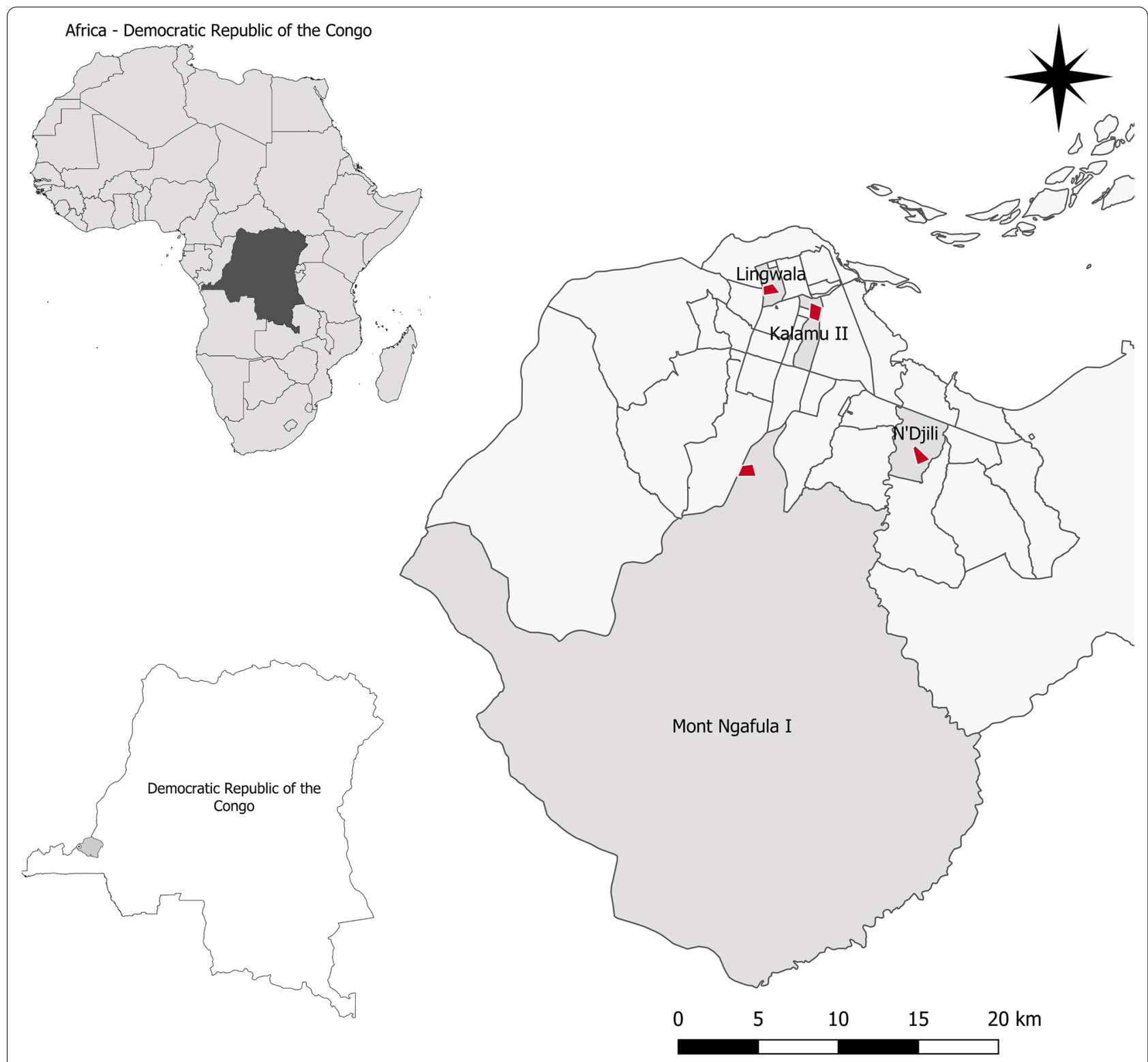

Fig. 1 Maps indicating the survey sites. The four survey communes (light grey) with sampling areas indicated by red dots, in Kinshasa, 2018 


\section{Study design and data collection}

Two cross-sectional surveys were undertaken, one in the rainy season (18 January-16 February 2018) and one in the dry season (2-27 July 2018). To identify $10 \%$ of the houses that were positive for Aedes spp. mosquitoes at $80 \%$ power, $3 \%$ precision and allowing for a $5 \% \alpha$-error, 400 houses needed to be surveyed in each survey site. In each of the four selected communes, one neighborhood was randomly chosen (all the neighborhoods per commune were listed, followed by a random number selection procedure) as the study site. Each day, 80 houses were inspected following a systematic sampling approach: random points were identified on a landmark (a roundabout or a main road) by each team as their starting point from which to enter (smaller) streets. With a sampling interval of three houses, starting on the right side of a street, each of the four teams inspected the selected houses up to a maximum of 20 houses/day. If the quota of 20 houses had not been met when the street came to an end, the team turned back and inspected the houses on the other side of the street in the same manner until the sample quota had been reached. Each selected house was inspected inside and outside. If there was more than one house per compound, a random house was chosen for inspection, but the entire outside area of the compound was inspected. The next day, the next street (going left from the street sampled on the previous day) was sampled. By following this procedure, representative sampling was achieved. When the inspection of one commune had been completed, the four entomological teams went to another commune and followed the same methodology. The inspection of all the communes was achieved within a period of 4 weeks. Each entomological survey team consisted of three people: one person previously trained by the entomology department of the Institut National de Recherche Biomédicale (INRB), one entomologist from the INRB (the supervisor), and one community health worker.

In each compound, all water-holding containers were inspected and if immature stages of mosquitoes (i.e. larvae or pupae) were observed, they were collected in plastic bottles (one bottle per larval habitat) and transported to the laboratory at INRB for identification to genus (Anopheles, Aedes, Culex). The location, category and positivity/negativity for mosquitoes of each container were recorded. For larvae, only positivity and negativity was recorded; for pupae, the number of pupae was counted per positive habitat. The surveys were implemented identically, but as samples were randomly selected, the houses had equal probability of inclusion in one, both, or neither survey. Both surveys were largely realized by the same field team members.

\section{Morphological and DNA-based species identification}

Each day, a random sample of 50 Aedes larvae/pupae were reared to adults in an insectarium to allow species identification using morphological keys [33, 34]. F0 adults were stored at $-20^{\circ} \mathrm{C}$ for DNA barcoding to validate the morphological identification of Ae. aegypti and Ae. albopictus and confirm the presence of the identified species in Kinshasa. Five specimens of each species were randomly selected per survey site for DNA barcoding. DNA barcoding is a technique based on the amplification of a standard barcode-the partial mitochondrial cytochrome $c$ oxidase subunit I (COI) gene for animals. Sanger sequencing of the 658-base pair COI standard barcode was performed using LCO1490 and HCO2198 universal primers $[35,36]$. Amplifications were carried out in a 20- $\mu \mathrm{l}$ reaction mixture containing $2 \mu \mathrm{l}$ of DNA template, $2 \mu \mathrm{l}$ of $10 \times$ buffer, $1.5 \mathrm{mM} \mathrm{MgCl}, 0.2 \mathrm{mM}$ $\mathrm{dNTP}, 0.4 \mu \mathrm{M}$ of each primer, and 0.03 units/ $\mu \mathrm{l}$ of Platinum Taq DNA Polymerase (Invitrogen). PCR products and negative controls were checked on a 1.5\% agarose gel, using a ultraviolet transilluminator and the MidoriGreen Direct (NIPPON Genetics Europe) method. Positive amplicons were purified using the ExoSAP-IT protocol and sequenced in both directions on an ABI 3230xl capillary DNA sequencer using BigDye Terminator v3.1 chemistry (ThermoFisher Scientific). The generated sequences were then compared to a library of reference sequences. Specimens were identified by analyzing their percentage sequence similarity with the reference sequences under the assumption that genetic diversity is lower within than between species. A rooted neighborjoining tree was constructed including a sub-selection of the Ae. albopictus and Ae. aegypti barcodes available from online repositories, together with the newly generated haplotypes (full details of the protocol can be found in Additional file 2).

\section{Data analysis}

Data were entered into the Microsoft Access database and $5 \%$ of the data were manually validated to detect errors. Data cleaning was undertaken and the types of recipients regrouped into categories, adapted from guidelines used in dengue-endemic regions [37], as follows: water storage tanks or cisterns (> 15 l); small water containers used for daily kitchen and cleaning activities $(<15 \mathrm{l})$; rubbish and discards; natural tree and bamboo holes; artificial containers that are used by households and cannot be destroyed (e.g. animal drinking pots); used tires; natural ground surface pools. Data were analyzed using IBM SPSS statistics, version 25. We calculated, per round of visits and per commune, the house index (HI; number of houses positive for at least one container with 
immature stages of Aedes spp. per 100 inspected houses), Breteau index (BI; number of containers positive for immature stages of Aedes spp. per 100 inspected houses), container index $(\mathrm{CI}$; number of containers positive for immature stages of Aedes spp. per 100 inspected containers), and pupal index (number of Aedes spp. pupae per 100 inspected houses). The relative contribution to pupal productivity, defined as the total number of pupae of Aedes spp. per category of larval habitat divided by the total number of pupae of Aedes spp. collected per commune and per survey round, was calculated. A descriptive analysis was done. In order to evaluate the factors determining Aedes spp. immature stage positivity, a logistic regression model was used and associated variables were identified based on a backwards conditional model, taking into account clustering at the household level by inserting the household identification variable as a random factor in the model.

The number of larval habitats with at least one immature stage of Anopheles spp. was enumerated and its proportional importance calculated for each season and respective commune.

\section{Results}

In the surveys, a total of 1678 and 1598 houses were sampled in the rainy and dry season, respectively. In the rainy season, 5079 water-holding containers (potential larval habitats) were inspected compared with 1657 in the dry season. The average number of containers per household varied across communes $(p<0.001)$, e.g. in the rainy season, there was an average of 1.4 (SD 1.3) in Kalamu, 2.0 (SD 1.7) in Lingwala, 2.9 (SD 2.3) in Mont Ngafula and 5.3 (SD 2.6) in N'Djili. In the rainy and dry season, $65.9 \%$ and $78.3 \%$ of the containers, respectively, were observed outside the sampled houses, i.e. in the open space within the compound $(p<0.001)$. The distribution of the types of containers per location, commune and season is given in more detail in Additional file 1 (Table 1).

Aedes larval indices were higher in the rainy than in the dry season $(p<0.001$; Table 2$)$, with a BI of 45.35 versus 10.39 positive containers/100 houses, a CI of $14.9 \%$ versus $10.02 \%$ and a $\mathrm{HI}$ of $27.53 \%$ versus $7.63 \%$, respectively (Table 1). Mont Ngafula, a rural sub-urban area on the southern edge of Kinshasa had the highest infestation levels amongst all the visited communes, with a BI of 82.21 and 19.50 positive containers/100 houses in the rainy and dry season, respectively, about four times higher than those of Kalamu, a commune that lies within the heart of the city. In the rainy season, the pupal index reached 246 pupae/100 houses in Mont Ngafula, 126 in N'Djili, 90 in Lingwala, and 50 in Kalamu (Table 1). In the rainy season, $99.3 \%$ of the positive larval habitats were outdoors versus $96.4 \%$ in the dry season. A wide variety of containers were occupied by Aedes mosquitoes as aquatic habitat: water storage tanks, small water deposits, rubbish/ dicards, bamboo/tree holes, non-destroyable artificial containers, used tires, natural ground pools (Fig. 2). Tires were treated as a separate group, as they were frequently present and it was difficult to know if they had been put aside for re-use/temporary storage or for destruction.

We observed a statistically significant difference between the pupal productivity of larval habitats in the rainy and dry seasons [adjusted odds ratio (aOR) 3.73, 95\% confidence interval $(2.21-6.31) ; p<0.001]$. In the dry season, $20.3 \%$ of pupal production was in water storage tanks versus $5.5 \%$ in the rainy season, which indicated seasonal variability in aquatic habitat preference

Table 1 Entomological indices for Aedes spp. for the four survey sites in the rainy and dry seasons, Kinshasa 2018

\begin{tabular}{|c|c|c|c|c|c|c|}
\hline & & Total & Lingwala & Ndjili & Mont Ngafula & Kalamu \\
\hline No. of containers inspected & Rainy/dry season & $5079 / 1657$ & $821 / 180$ & $2550 / 665$ & $1164 / 634$ & $544 / 178$ \\
\hline \multirow[t]{2}{*}{ Container index $(\%)^{\mathrm{a}}$} & Rainy season & 14.98 & 17.90 & 7.84 & 28.18 & 15.81 \\
\hline & Dry season & 10.02 & 21.67 & 4.51 & 12.30 & 10.67 \\
\hline No. of houses inspected & Rainy/dry season & $1678 / 1598$ & $400 / 399$ & $479 / 399$ & $399 / 400$ & $400 / 400$ \\
\hline \multirow{2}{*}{$\begin{array}{l}\text { Breteau index (no. positive containers/100 } \\
\text { houses) }^{b}\end{array}$} & Rainy season & 45.35 & 36.75 & 41.75 & 82.21 & 21.50 \\
\hline & Dry season & 10.39 & 9.77 & 7.52 & 19.50 & 4.75 \\
\hline \multirow[t]{2}{*}{ House index $(\%)^{c}$} & Rainy season & 27.53 & 22.25 & 27.97 & 44.86 & 15.00 \\
\hline & Dry season & 7.63 & 7.02 & 6.52 & 13.25 & 3.75 \\
\hline \multirow[t]{2}{*}{ Pupal index (no. pupae/100 houses) ${ }^{d}$} & Rainy season & 128.00 & 90.00 & 126.00 & 246.00 & 50.00 \\
\hline & Dry season & 15.00 & 13.00 & 9.00 & 20.00 & 19.00 \\
\hline
\end{tabular}

\footnotetext{
a Number of containers positive for immature stages of Aedes spp. per 100 inspected containers

b Number of containers positive for immature stages of Aedes spp. per 100 inspected houses

c Number of houses positive for at least one container with immature stages of Aedes spp. per 100 inspected houses

d Number of Aedes spp. pupae per 100 inspected houses
} 
of the vectors (Fig. 3). In the rainy season, $64.3 \%$ of all inspected containers were small water containers, but these were only responsible for $46.4 \%$ of the pupal production, whereas used tires, representing only $11.1 \%$ of the inspected containers, were responsible for $35.0 \%$ of the pupal production. The containers used for water storage (big and small) contributed relatively more to pupal productivity in the dry season than in the rainy season. Furthermore, the pupal productivity of artificial containers (mainly rubbish) was different across communities $(p<0.001)$ and season $(p<0.001)$ (Fig. 4).

Positivity for Aedes was higher in the rainy than in the dry season with an aOR of 1.98 (95\% confidence interval 1.6-2.4), and was about 27 times [aOR 27.4 (95\% confidence interval 14.9-50.1)] higher outdoors than indoors $(p<0.001)$. Mont Ngafula and Lingwala were statistically significantly more infested than N'Djili $(p<0.001$; Table 2). The types of water container most associated with Aedes infestation were used tires [aOR 4.6 (95\% confidence interval 3.5-6.1)] and rubbish/discards [aOR 1.9 (95\% confidence interval 1.4-2.5)], rather than water storage tanks (Table 2).

Based on morphological identification, F0 adult Ae. aegypti and Ae. albopictus were present in both seasons and at all study sites. Morphological identification was validated by comparing the generated sequences of a subset of specimens against the BOLD Identification System with Species Level Barcode Records. The obtained similarity percentages ranged from 99.69 to $100 \%$. The five and 14 haplotypes of Ae. albopictus and Ae. aegypti,

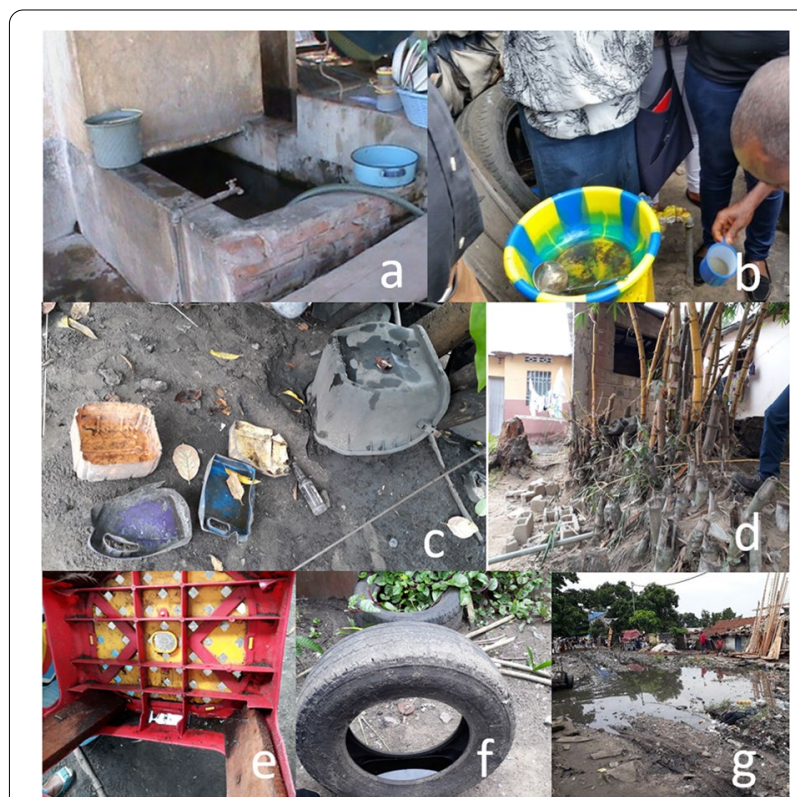

Fig. 2a-g Photos of various types of larval habitat identified/ investigated in the study area. a Water storage tanks or cisterns (> $15 \mathrm{I})$; $\mathbf{b}$ small water containers (< $15 \mathrm{I}$ ) used for daily kitchen and cleaning activities; $\mathbf{c}$ rubbish and discards; $\mathbf{d}$ natural tree and bamboo holes; e artificial containers that are used by households and cannot be destroyed (e.g. animal drinking pots); $\mathbf{f}$ used tires; $\mathbf{g}$ natural ground surface pools

respectively, only clustered with sequences from conspecific specimens collected worldwide (Fig. 5); this was supported by maximum bootstrap results (Additional

Table 2 Determinants of Aedes spp.-positive larval habitats in Kinshasa, 2018

\begin{tabular}{|c|c|c|c|c|c|}
\hline \multirow[t]{2}{*}{ Parameter } & \multirow[t]{2}{*}{ Category } & \multirow[t]{2}{*}{ Total } & \multirow[t]{2}{*}{ Positive $[n(\%)]$} & \multicolumn{2}{|l|}{ Multivariate } \\
\hline & & & & $\begin{array}{l}\text { Odds ratio ( } 95 \% \text { confidence } \\
\text { interval) }\end{array}$ & $p$-value \\
\hline \multirow[t]{2}{*}{ Season } & Rainy & 5079 & $761(15.0)$ & $1.98(1.63-2.40)$ & $<0.001$ \\
\hline & Dry & 1657 & $166(10.0)$ & 1 & \\
\hline \multirow[t]{4}{*}{ Commune } & Kalamu & 722 & $105(14.5)$ & $0.97(0.74-1.28)$ & 0.857 \\
\hline & Lingwala & 1001 & $186(18.6)$ & $1.53(1.20-1.96)$ & 0.001 \\
\hline & Mont Ngafula & 1798 & $406(22.6)$ & $2.67(2.19-3.25)$ & $<0.001$ \\
\hline & N'Djili & 3215 & $230(7.2)$ & 1 & \\
\hline \multirow[t]{2}{*}{ Position } & Exterior & 4646 & $916(19.7)$ & $27.36(14.9-50.1)$ & $<0.001$ \\
\hline & Interior & 2090 & $11(0.5)$ & 1 & \\
\hline \multirow[t]{7}{*}{ Container type } & Water storage tanks & 1080 & $94(8.7)$ & 1 & \\
\hline & $\begin{array}{l}\text { Small water containers (small water } \\
\text { deposits) }\end{array}$ & 4373 & $395(9.0)$ & $0.99(0.77-1.27)$ & 0.918 \\
\hline & Rubbish & 533 & $134(25.1)$ & $1.89(1.39-2.55)$ & $<0.001$ \\
\hline & Bamboo hole & 5 & $0(0)$ & 0 & 1 \\
\hline & Artificials not destroyable & 18 & $4(22.2)$ & $0.998(0.32-3.13)$ & 0.997 \\
\hline & Used tires & 710 & $296(41.7)$ & $4.60(3.50-6.06)$ & $<0.001$ \\
\hline & Ground pools & 17 & $4(23.5)$ & $2.06(0.62-6.79)$ & 0.236 \\
\hline
\end{tabular}




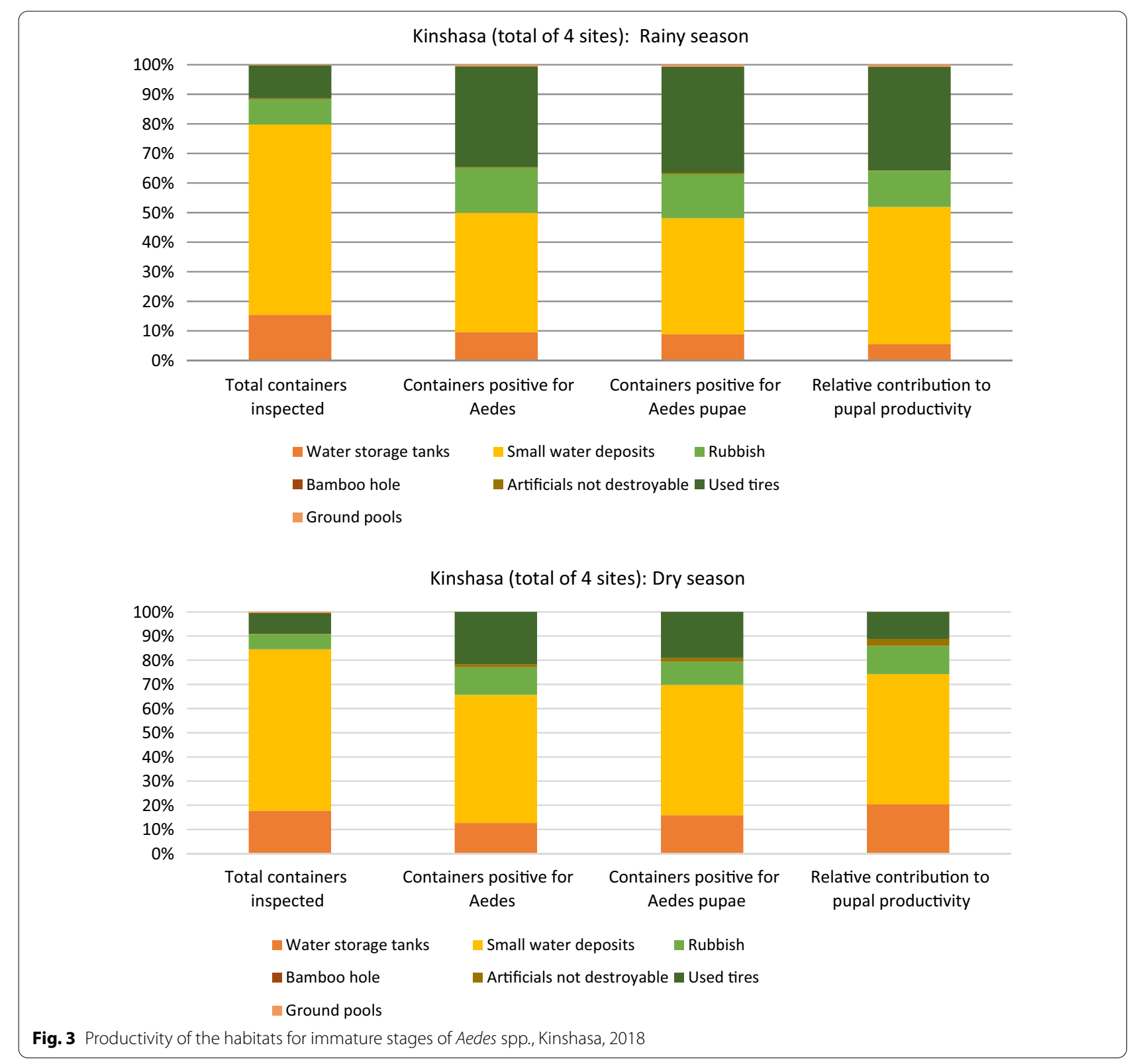

file 2: Figure S1). The generated sequences were deposited in GenBank with the following accession numbers: MT345349-MT345426.

Among containers positive for Aedes spp. immature stages, $9.46 \%$ and $9.06 \%$ also contained immature stages of other genera, such as Culex and Anopheles, in the rainy and dry season, respectively. In $99.3 \%$ of the outdoor recipients, and specifically in water storage tanks in the rainy season and in trash in the dry season, habitats were shared. In the rainy season, a total of 32 Aedes larval habitats were positive for Anopheles versus only two in the dry season. Anopheles were found in big and small water deposits, rubbish and used tires (Fig. 6). In the rainy season, Anopheles were observed in all communes, whereas in the dry season, Anopheles larvae were only found in small water deposits in Mont Ngafula, the most rural commune of the four survey sites (Fig. 7).

\section{Discussion}

In both surveys, in all the communes studied, the larval indices ( $\mathrm{HI}, \mathrm{CI}$, and $\mathrm{BI}$ ) were higher than the arbovirus transmission threshold values established by the World Health Organization (BI of 5) $[38,39]$. As the BI was, on average, 45 positive containers/100 houses in the rainy 


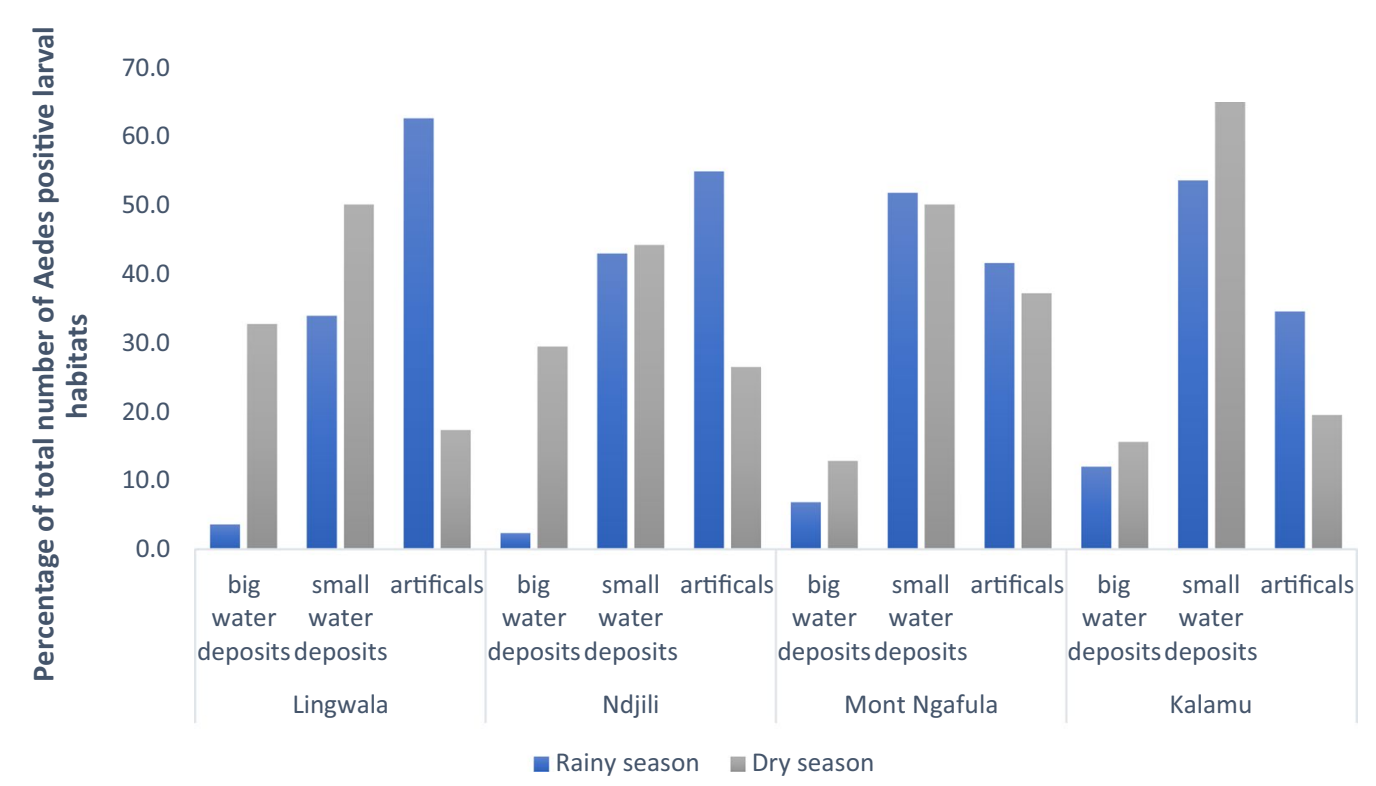

Fig. 4 Geographical and seasonal differences of the most productive habitats for Aedes spp. larvae, Kinshasa, 2018

season, and the $\mathrm{HI}$, on average, $27 \%$, it is clear that one household can have different Aedes spp.-positive larval habitats. Should an arbovirus be introduced into Kinshasa in the future, the high larval and pupal Aedes densities found in the present study suggest that transmission could rapidly occur and lead to a major outbreak of disease, such as that seen for chikungunya in 2019 [23].

The standardized procedure used for the surveys in the four different communes of Kinshasa during the rainy and dry seasons is the major strength of this study. The members of the entomological team were trained before the study, and were largely the same in both surveys. A weakness of this study is that the surveys took place over only 1 year and only once per season. As the inspection of the larval habitats depended on the rigor and professionalism of the team doing the fieldwork, quality control was established by ensuring that a supervisor was available in the field site during the survey, and regular additional quality control was also undertaken by international members of the survey team. Due to operational issues, we were not in a position to identify all the larvae to species level; this was only done for a small subsample of larvae, hence we could not calculate the specific relative importance of Ae. aegypti and Ae. albopictus, but only observe a tendency for their equal presence. Neither could we calculate which species has a predilection for which container type. Ae. aegypti and Ae. albopictus display different vector competence for different arboviruses, and more detailed information on the occurrence of each vector would allow us to develop more precise control measures in the case of a specific arbovirus outbreak. Aedes aegypti, which originated in Africa, is the main vector of arboviruses globally, but its vector competence is highly variable and depends on the vector population, the virus isolate and the ecological context [28]. The presence of Ae. albopictus, which is an exotic species in Africa, might change the epidemiology of a number of arboviruses in Africa [40]. In several chikungunya epidemics, Ae. albopictus has been shown to be the main driver of transmission of the chikungunya virus, especially in the case of the East/Central/South African lineage with A226V mutation, as shown in a recent outbreak in Kinshasa [41].

In a place like Kinshasa, where dengue is rarely reported [11-14], and there are only sporadic outbreaks of chikungunya and yellow fever [21, 23, 42], the high Aedes larval and pupal indices found in the present study are unexpected. The indices observed here are comparable to those reported for other African settings, e.g. southeastern Tanzania has a HI of 4.9-6.6, and CI of 14.6-18.9 [43]; Burkina Faso has a HI of 70, a CI of 35 and a BI of 10 [44]; northwest Ethiopia has a HI of 25.5, a CI of 32.9 and a BI of 48.4 [45]; Mozambique has a CI of 22 [46]; and Angola has a HI of 4.3-27.9, a CI of 2.1-9.3 and a BI of 5.8-42.2 [47]. However, the Aedes larval and pupal indices found in the present study are much lower than those observed in Kenya during a dengue outbreak in 2013-2014, where the BI reached a value of 270 positive containers/100 houses [48].

In contrast to findings from Latin-America [49], in Kinshasa, immature stages of Aedes were found in 


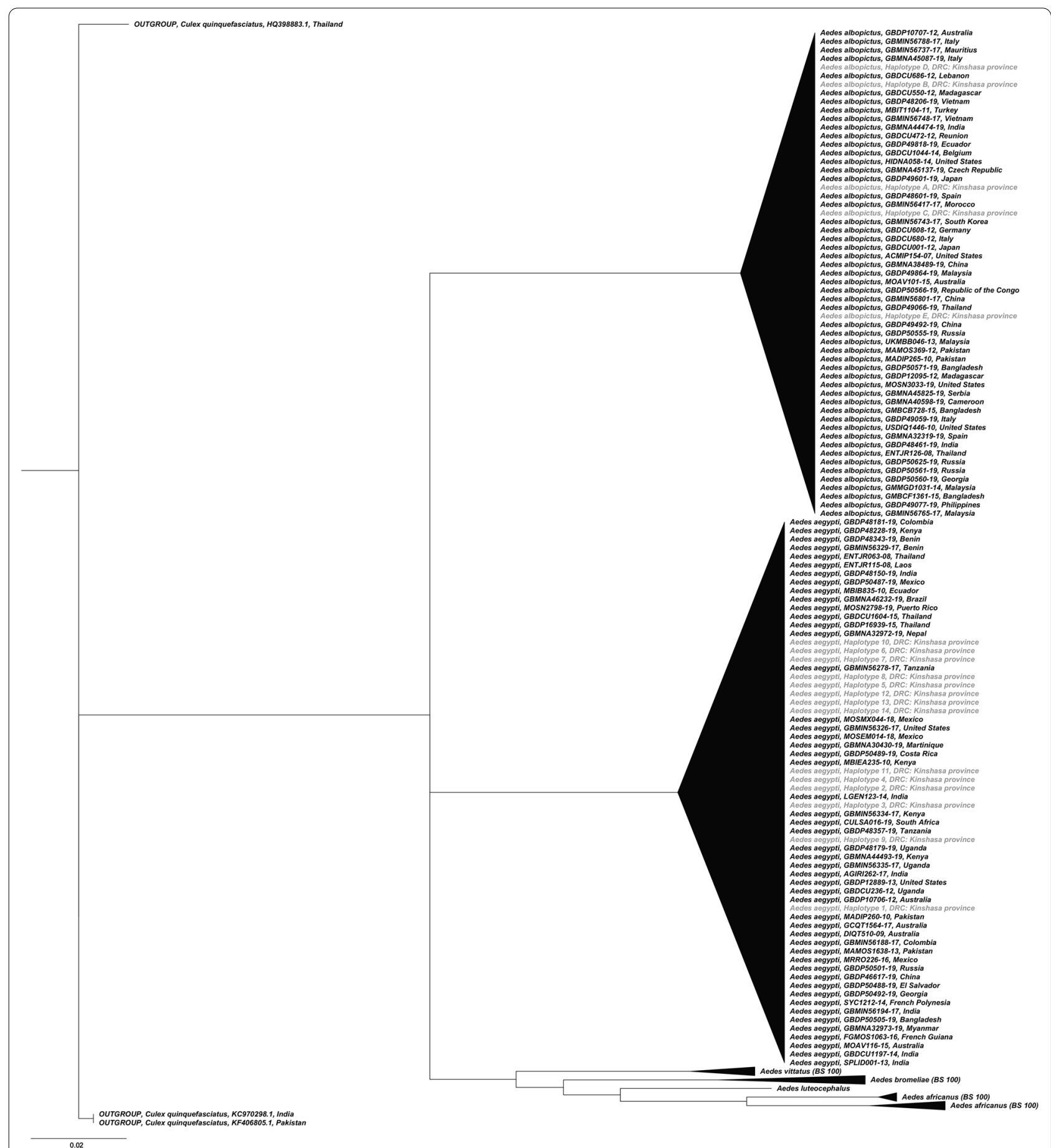

Fig. 5 Neighbor-joining tree including the six medically important Aedes species of the subgenus Stegomyia occurring in the Afrotropical region. The generated haplotypes of Aedes albopictus and Aedes aegypti specimens of the Democratic Republic of Congo are highlighted in grey

$19.7 \%(916 / 4646$ containers) of the outdoor containers versus $0.5 \%(11 / 2090)$ of the indoor containers. These differences between the number of immature stages of Aedes indoors and outdoors are characteristic of findings for other African countries [50]. The prevalence of Aedes larval habitats outdoors together with the behavior of Aedes in this context (remaining outside in the backyard or in the open in front of a house and blood feeding on humans during the day) suggests that there is a close relationship between humans and 

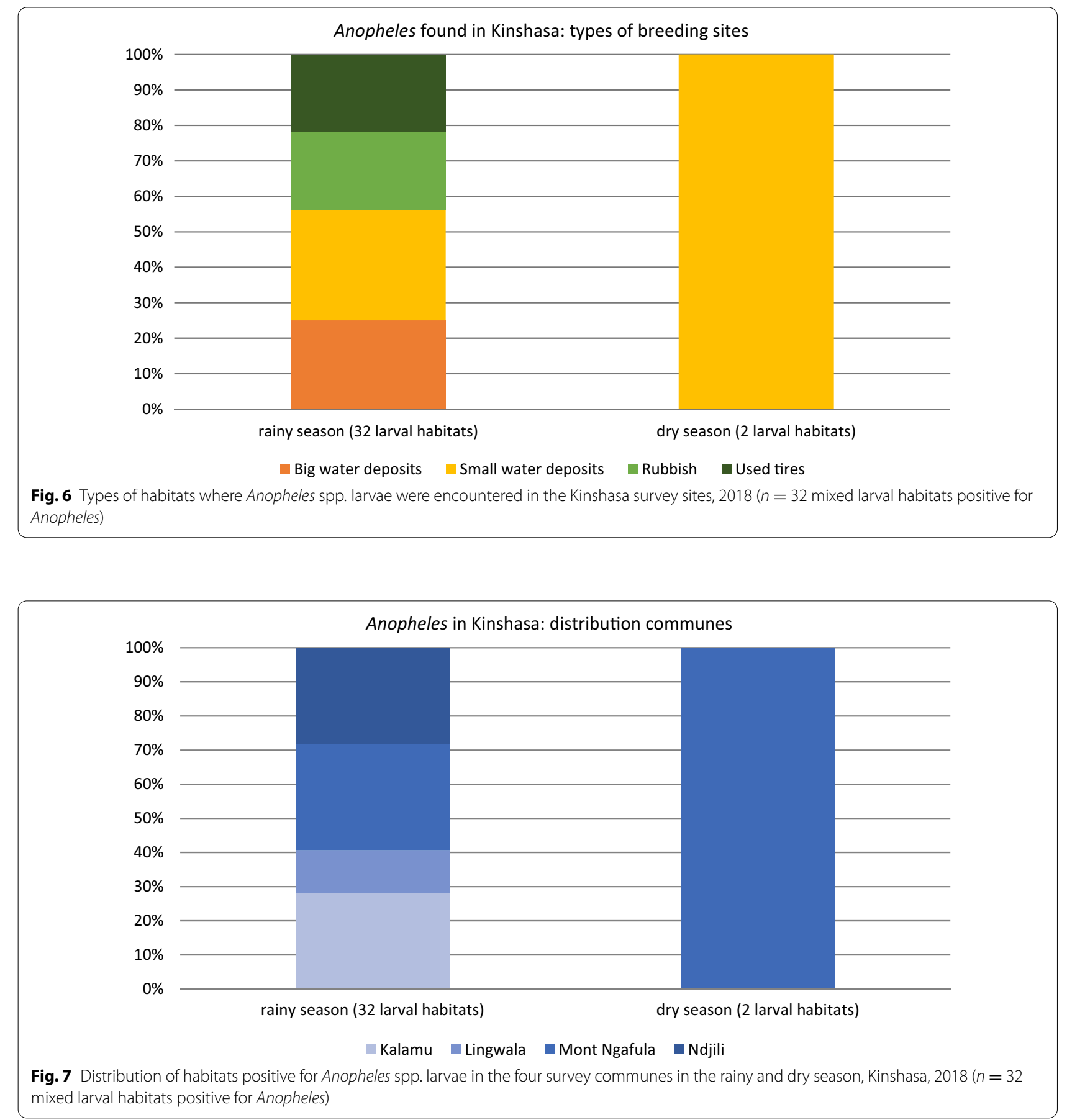

these mosquitoes, which favors the life cycle of Aedes spp. [51]. The low presence of immature stages of Aedes inside the houses could also have been a consequence of the rapid use of water from, and the cleaning of, the containers found there. These results indicate that management strategies for the control of Aedes in Kinshasa need to target outdoor spaces for the destruction or reduction of larval habitats.

Used car tires, water storage tanks and other artificial larval habitats (type rubbish/discards) were the main types of container chosen by Aedes mosquitoes for oviposition, which is in agreement with other 
studies conducted on these mosquitoes in Africa [44-48, 50,52]. Water storage tanks were found to be the most productive containers for the pupal stage of Aedes, which is the non-feeding stage preceding the adult stage [53]. The water storage tanks are always kept partially or fully filled with water irrespective of rainfall due to the deficient water supply system, which makes them a preferred larval habitat, especially in the dry season, even though they are constantly subject to anthropogenic activity. In the rainy season, larval habitats were favored by rainfall in all the survey sites, and the containers typically filled with rainwater were the most productive ones for Aedes pupae. Old tires are illustrative of this, as while they only represent $11 \%$ of the potential larval habitats, in the rainy season, about $35 \%$ of all of the pupae were found in them. The temperature, humidity and reduced light inside tires create a suitable environment for Aedes reproduction, and when tires are stored or have been discarded for a long period of time without being scrubbed, larvae can proliferate in them [54-56]. Under such conditions, eggs can also remain attached to tires for a long period of time, and tires thus play a role in the preservation of the Aedes mosquito population throughout the dry season [57]. The disproportionate importance of certain containers for pupae-and hence for the production of adult Aedes-identified in the present study is useful as it indicates which key larval habitats should be targeted in management strategies that are designed to decrease arbovirus transmission risk.

In this study, Aedes spp., which are vectors of chikungunya, dengue, Zika and yellow fever, were dominant in the potential larval habitats that were inspected in and around the houses. Other mosquito genera were also found, such as Culex and Anopheles. While Culex may share larval habitats with urban species of Aedes, it is unusual to find Anopheles species together with Aedes [58]. Anopheles usually prefer other types of larval habitats, such as ponds with static fresh water, and are not particularly attracted to small containers [59]. The presence of Anopheles in urban settings was previously thought to be associated with urban agriculture, as previously seen in Mont Ngafula [60]. However, we found Anopheles in all four communes in the rainy season, in the absence of agriculture. Anopheles needs to be identified to species level in each of the different communes, especially in the context of the invasion of Anopheles stephensi into eastern Africa [61]. The presence of Anopheles larvae in man-made containers suggests that Anopheles species can adapt to diverse containers, which in turn indicates a heightened transmission risk of malaria in urban Kinshasa.

\section{Conclusion}

Aedes spp. seem to be well established in all of the four communes of Kinshasa surveyed here, and are especially abundant in the suburban area of Mont Ngafula. This study, which to our knowledge is the first of its kind to be carried out in Kinshasa, shows that Aedes control strategies here need to target outdoor containers, specifically those designed for water storage, in the dry season, and tires in the rainy season. Additional insights into the ecology of adult Aedes mosquitoes and their susceptibility to insecticides will support the design of a comprehensive Aedes control strategy for the prevention of further outbreaks of arboviral diseases in Kinshasa.

\section{Supplementary Information}

The online version contains supplementary material available at https://doi. org/10.1186/s13071-021-04588-7.

Additional file 1: Table S1. Distribution of inspected containers inside/ outside the houses, Kinshasa 2018.

Additional file 2. DNA based species validation (methods, results and Figure S1).

\section{Abbreviations}

DRC: Democratic Republic of Congo; INRB: Institut National de Recherche Biomédicale; BI: Breteau index; Cl: Container index; HI: House index; aOR: Adjusted odds ratio.

\section{Acknowledgements}

We would like to express our sincere gratitude to all the inhabitants of the four communes who participated in this study, and to Isaac Pankwa at INRB, Kinshasa for the data entries.

\section{Authors' contributions}

FWT, MCM and VV designed the study; EMZ, and WVB supervised the survey and the laboratory work; SF organized the fieldwork; GBM, GI and RMT realized the fieldwork; MCM, GBM, GI and WVB did the laboratory work; NS did the DNA barcoding; W and WVB did the data analysis; JAB, WVB, MCM interpreted the results. All the authors wrote part of the manuscript. All the authors read and approved the final manuscript.

\section{Funding}

We acknowledge the financial support of the Directorate-General for Development Co-operation, Belgium (FA4) for the institutional collaboration between INRB, DRC and the Institute of Tropical Medicine, Belgium. The Institute of Tropical Medicine's outbreak research team is supported by the Department of Economy, Science and Innovation of the Flemish government, Belgium. The Barcoding Facility for Organisms and Tissues of Policy Concern (BopCo-http://bopco.myspecies.info/) is financed by the Belgian Science Policy Office as the Belgian federal in-kind contribution to the LifeWatch European Research Infrastructure Consortium. The funding bodies did not have any role in the design of the study or in the collection, analysis, or interpretation of the data, or in the writing of the manuscript.

\section{Availability of data and materials}

The datasets used and/or analyzed during the current study are available from the corresponding author on reasonable request.

\section{Ethics approval and consent to participate}

The study protocol was approved by the Comité d'éthique de l'Université de Kinshasa (authorization number: ESP/CE/032/2018). Before starting the survey in each commune, the study was presented to the Médecin Chef de Zone 
and the local mayor, in order to have their approval to realize the study in their area of responsibility. Informed consent was asked of each head of household of the sampled houses, and oral agreement was obtained. Different quality control measures were put in place: in each commune an entomologist supervised the work of the field teams, the project leader verified at the end of each day a subset of the data collection forms for their completeness, and an external entomologist (a Cuban expert) carried out ad hoc supervision of the fieldwork and laboratory activities.

\section{Consent for publication}

Not applicable.

\section{Competing interests}

The authors declare that they have no competing interests.

\section{Author details}

${ }^{1}$ Unit of Entomology, Department of Parasitology, National Institute of Biomedical Research, 5345 Avenue De la Démocratie, Gombe, Kinshasa, Democratic Republic of the Congo. ${ }^{2}$ Department of Vector Control, Instituto Medicina Tropical Pedro Kourí (IPK), Avenida Novia del Mediodía, KM 6 1/2, La Lisa, Havana, Cuba. ${ }^{3}$ Department of Biology, Royal Museum for Central Africa (BopCo), Leuvensesteenweg 13-17, Tervuren, Belgium. ${ }^{4}$ Outbreak Research Team, Institute of Tropical Medicine (ITM), Nationalestraat 155, Antwerp, Belgium. ${ }^{5}$ Unit of Entomology, Biomedical Science Department, Institute of Tropical Medicine (ITM), Nationalestraat 155, Antwerp, Belgium. ${ }^{6}$ Tropical Infectious Disease Group, Public Health Department, Institute of Tropical Medicine (ITM), Nationalestraat 155, Antwerp, Belgium.

Received: 22 June 2020 Accepted: 8 January 2021 Published online: 01 February 2021

\section{References}

1. Nsoesie EO, Kraemer MUG, Golding N, Pigott DM, Brady OJ, Moyes CL, et al. Global distribution and environmental suitability for chikungunya virus, 1952 to 2015. Euro Surveill. 2016;21(20):10.

2. Weaver SC, Reisen WK. Present and future arboviral threats. Antiviral Res. 2010;85(2):328-45.

3. Roth A, Mercier A, Lepers C, Hoy D, Duituturaga S, Benyon E, et al. Concurrent outbreaks of dengue, chikungunya and Zika virus infections - an unprecedented epidemic wave of mosquito-borne viruses in the Pacific 2012-2014. Euro Surveill. 2014;19(41):1-8.

4. Bhatt S, Gething PW, Brady OJ, Messina JP, Farlow AW, Moyes CL, et al. The global distribution and burden of dengue. Nature. 2013;496(7446):504-7.

5. Freitas LP, Cruz OG, Lowe R, Carvalho MS. Space-time dynamics of a triple epidemic: dengue, chikungunya and Zika clusters in the city of Rio de Janeiro. Proc R Soc B Biol Sci. 1912;2019(286):20191867.

6. Bhoomiboonchoo P, Gibbons RV, Huang A, Yoon IK, Buddhari D, Nisalak A, et al. The spatial dynamics of dengue virus in Kamphaeng Phet, Thailand. PLoS Negl Trop Dis. 2014;8(9):6-11.

7. Amarasinghe A, Kuritsky JN, William Letson G, Margolis HS. Dengue virus infection in Africa. Emerg Infect Dis. 2011;17(8):1349-54.

8. Ngoagouni C, Kamgang B, Nakouné E, Paupy C, Kazanji M. Invasion of Aedes albopictus (Diptera: Culicidae) into central Africa: what consequences for emerging diseases? Parasites Vectors. 2015;8:191.

9. Kraemer MUG, Sinka ME, Duda KA, Mylne AQN, Shearer FM, Barker CM, et al. The global distribution of the arbovirus vectors Aedes aegypti and Ae. albopictus. Elife. 2015:4:1-18.

10. Ward T, Samuel M, Maoz D, Runge-Ranzinger S, Boyce R, Toledo J, et al. Dengue data and surveillance in Tanzania: a systematic literature review. Trop Med Int Health. 2017;22(8):960-70.

11. Ido E, Ahuka S, Karhemere S, Ibuki K, Shibata M, Kameoka M, et al. Dengue virus infection during an outbreak of chikungunya virus in Democratic Republic of Congo/Infection du virus de la Dengue survenue lors d'une épidémie du virus Chikungunya en République démocratique du Congo. Ann Afr Med. 2016. https://anafrimed.net/dengue-virus-infec tion-during-an-outbreak-of-chikungunya-virus-in-democratic-republicof-congo-infection-virus-de-dengue-survenue-lors-dune-epidemie-virus -chikungunya-republique-democr/. Accessed 17 Mar 2020.
12. Willcox AC, Collins MH, Jadi R, Keeler C, Parr JB, Mumba D, et al. Seroepidemiology of dengue, Zika, and yellow fever viruses among children in the Democratic Republic of the Congo. Am J Trop Med Hyg. 2018;99(3):756-63.

13. Makiala-Mandanda S, Ahuka-Mundeke S, Abbate JL, Pukuta-Simbu E, Nsio-Mbeta J, Berthet N, et al. Identification of dengue and chikungunya cases among suspected cases of yellow fever in the Democratic Republic of the Congo. Vector Borne Zoonotic Dis. 2018;18(7):364-70.

14. Proesmans S, Katshongo F, Milambu J, Fungula B, Mavoko HM, AhukaMundeke $S$, et al. Dengue and chikungunya among outpatients with acute undifferentiated fever in Kinshasa, Democratic Republic of Congo: a crosssectional study. PLoS Negl Trop Dis. 2019;13(9):1-16.

15. Sharp TM, Moreira R, Soares MJ, da Costa LM, Mann J, DeLorey M, et al. Underrecognition of dengue during 2013 epidemic in Luanda, Angola. Emerg Infect Dis. 2015;21(8):1311-6.

16. Chretien JP, Anyamba A, Bedno SA, Breiman RF, Sang R, Sergon K, et al. Drought-associated chikungunya emergence along coastal East Africa. Am J Trop Med Hyg. 2007;76(3):405-7.

17. Crump JA, Morrissey AB, Nicholson WL, Massung RF, Stoddard RA, Galloway RL, et al. Etiology of severe non-malaria febrile illness in northern Tanzania: a prospective cohort study. PLoS Negl Trop Dis. 2013;7(7):e2324.

18. Mugabe VA, Ali S, Chelene I, Monteiro VO, Guiliche O, Muianga AF, et al. Evidence for chikungunya and dengue transmission in Quelimane, Mozambique: results from an investigation of a potential outbreak of chikungunya virus. PLoS ONE. 2018;13(2):e0192110.

19. Moyen N, Thiberville SD, Pastorino B, Nougairede A, Thirion L, Mombouli $\mathrm{J}$, et al. First reported chikungunya fever outbreak in the Republic of Congo, 2011. PLoS ONE. 2014;9(12):e115938.

20. Fritz M, Taty Taty R, Portella C, Guimbi C, Mankou M, Leroy EM, et al. Reemergence of chikungunya in the Republic of the Congo in 2019 associated with a possible vector-host switch. Int J Infect Dis. 2019;84:99-101.

21. Pastorino B, Muyembe-Tamfum JJ, Bessaud M, Tock F, Tolou H, Durand JP, et al. Epidemic resurgence of chikungunya virus in Democratic Republic of the Congo: identification of a new central African strain. J Med Virol. 2004;74(2):277-82.

22. Malekani MJ, McCollum A, Monroe BP, Malekani VD, Mulumba ML, Tshilenge CG, Kondas A, Doty JB, Okitolonda EW, Muyembe JJT, Kabamba J, Nguete BKS. Cas de dengue chez les patients suspects de Chikungunya à Kinshasa. Ann Afr Med. 2014. https://anafrimed.net/cas-de-dengu e-chez-les-patients-suspects-de-chikungunya-a-kinshasa/. Accessed 17 Mar 2020.

23. World Health Organization. WHO | Chikungunya-Congo. World Health Organization. 2019. https://www.who.int/csr/don/01-may-2019-chiku ngunya-congo/en/. Accessed 17 Mar 2020.

24. Grossi-Soyster EN, Cook EAJ, de Glanville WA, Thomas LF, Krystosik AR, Lee J, et al. Serological and spatial analysis of alphavirus and flavivirus prevalence and risk factors in a rural community in western Kenya. PLoS Negl Trop Dis. 2017;11(10):e0005998.

25. Mbanzulu KM, Mboera LEG, Luzolo FK, Wumba R, Misinzo G, Kimera SI. Mosquito-borne viral diseases in the Democratic Republic of the Congo: a review. Parasites Vectors. 2020;13(1):103.

26. Kraemer MUG, Brady OJ, Watts A, German M, Hay SI, Khan K, et al. Zika virus transmission in Angola and the potential for further spread to other African settings. Trans R Soc Trop Med Hyg. 2017;111(11):527-9.

27. Grobbelaar AA, Weyer J, Moolla N, Van Vuren PJ, Moises F, Paweska JT. Resurgence of yellow fever in Angola, 2015-2016. Emerg Infect Dis. 2016;22(10):1854-5

28. Weetman D, Kamgang B, Badolo A, Moyes CL, Shearer FM, Coulibaly M, et al. Aedes mosquitoes and Aedes-borne arboviruses in Africa: current and future threats. Int J Environ Res Public Health. 2018;15(2):1-20.

29. Honório NA, Nogueira RMR, Codeço CT, Carvalho MS, Cruz OG, Magalhães MDAFM, et al. Spatial evaluation and modeling of dengue seroprevalence and vector density in Rio de Janeiro, Brazil. PLoS Negl Trop Dis. 2009;3(11):1-11.

30. Kamgang B, Happi JY, Boisier P, Njiokou F, Hervé JP, Simard F, et al. Geographic and ecological distribution of the dengue and chikungunya virus vectors Aedes aegypti and Aedes albopictus in three major Cameroonian towns. Med Vet Entomol. 2010;24(2):132-41.

31. Fontenille D, Toto JC. Aedes (Stegomyia) albopictus (Skuse), a potential new dengue vector in southern Cameroon. Emerg Infect Dis. 2001;7(6):1066-7. 
32. Bobanga T, Moyo M, Vulu F, Irish SR. First report of Aedes albopictus (Diptera: Culicidae) in the Democratic Republic of Congo. Afr Entomol. 2018;26(1):234-6.

33. Huang Y-M. The subgenus Stegomyia of Aedes in the Afrotropical region with keys to the species (Diptera: Culicidae). Zootaxa. 2004;700:120.

34. Rueda LM. Pictorial keys for the identification of mosquitoes (Diptera: Culicidae) associated with dengue virus transmission. Zootaxa. 2004;589:1-60.

35. Hebert PDN, Cywinska A, Ball SL, DeWaard JR. Biological identifications through DNA barcodes. Proc R Soc B Biol Sci. 2003;270(1512):313-21.

36. European and Mediterranean Plant Protection Organization. PM 7/129 (1) DNA barcoding as an identification tool for a number of regulated pests. EPPO Bull. 2016;46(3):501-37.

37. World Health Organization, TDR. Operational guide for assessing the productivity of Aedes aegypti breeding sites. 2011.

38. Focks DA, Brenner RJ, Hayes J, Daniels E. Transmission thresholds for dengue in terms of Aedes aegypti pupae per person with discussion of their utility in source reduction efforts. Am J Trop Med Hyg. 2000;62(1):11-8.

39. Sanchez L, Vanlerberghe V, Alfonso L, Marquetti MDC, Guzman MG, Bisset $J$, et al. Aedes aegypti larval indices and risk for dengue epidemics. Emerg Infect Dis. 2006;12(5):800-6.

40. Vega-Rua A, Zouache K, Girod R, Failloux A-B, Lourenco-de-Oliveira R. High level of vector competence of Aedes aegypti and Aedes albopictus from ten American countries as a crucial factor in the spread of chikungunya virus. J Virol. 2014;88(11):6294-306.

41. Selhorst P, Makiala-Mandanda S, De Smet B, Mariën J, Anthony C, BineneMbuka $G$, et al. Molecular characterization of chikungunya virus during the 2019 outbreak in the Democratic Republic of the Congo. Emerg Microbes Infect. 2020;9(1):1912-8.

42. Otshudiema JO, Ndakala NG, Mawanda E-TK, Tshapenda GP, Kimfuta JM, Loupy-Régence N, et al. Yellow fever outbreak-Kongo Central Province, Democratic Republic of the Congo, August 2016. Morb Mortal Wkly Rep. 2017:66(12):335-8.

43. Kahamba NF, Limwagu AJ, Mapua SA, Msugupakulya BJ, Msaky DS, Kaindoa EW, et al. Habitat characteristics and insecticide susceptibility of Aedes aegypti in the Ifakara area, south-eastern Tanzania. Parasites Vectors. 2020;13(1):53.

44. Ouattara LPE, Sangaré I, Namountougou M, Hien A, Ouari A, Soma DD, et al. Surveys of arboviruses vectors in four cities stretching along a railway transect of Burkina Faso: risk transmission and insecticide susceptibility status of potential vectors. Front Vet Sci. 2019;6:1-9.

45. Ferede G, Tiruneh M, Abate E, Kassa WJ, Wondimeneh Y, Damtie D, et al. Distribution and larval breeding habitats of Aedes mosquito species in residential areas of northwest Ethiopia. Epidemiol Health 2018;40:e2018015.

46. Abílio AP, Abudasse G, Kampango A, Candrinho B, Sitoi S, Luciano J, et al. Distribution and breeding sites of Aedes aegypti and Aedes albopictus in 32 urban/peri-urban districts of Mozambique: implication for assessing the risk of arbovirus outbreaks. PLoS Negl Trop Dis. 2018;12(9):1-15.

47. Marquetti C, Flores YH. Spatial distribution and mainly breeding sites of Aedes aegypti (Diptera: Culicidae) in Luanda, Angola. Ann Community Med Pract. 2017;3(1):1017.

48. Lutomiah J, Barrera R, Makio A, Mutisya J, Koka H, Owaka S, et al. Dengue outbreak in Mombasa City, Kenya, 2013-2014: entomologic investigations. PLoS Negl Trop Dis. 2016;10(10):2013-4.
49. Bisset Lazcano JA, Marquetti Fernández MdC, Rodríguez Coto MM. Contribution of entomological studies about Aedes aegypti and Aedes albopictus. Retrospective analysis and challenges for their control in Cuba, 1981-2016. Rev Cubana Med Trop. 2017;69(3):1-20.

50. Ngugi HN, Mutuku FM, Ndenga BA, Musunzaji PS, Mbakaya JO, Aswani P, et al. Characterization and productivity profiles of Aedesaegypti (L.) breeding habitats across rural and urban landscapes in western and coastal Kenya. Parasites Vectors. 2017;10(1):1-12.

51. Chadee DD. Resting behaviour of Aedes aegypti in Trinidad: with evidence for the re-introduction of indoor residual spraying (IRS) for dengue control. Parasites Vectors. 2013;6(1):1.

52. Kamgang B, Wilson-Bahun TA, Irving H, Kusimo MO, Lenga A, Wondji CS Geographical distribution of Aedes aegypti and Aedesalbopictus (Diptera: Culicidae) and genetic diversity of invading population of Ae. albopictus in the Republic of the Congo. Wellcome Open Res. 2018;3:1-18.

53. Focks DA, Daniels E, Keesling AE. A simulation model of the epidemiology of urban dengue fever: literature analysis, model development, preliminary validation, and samples of simulation results. Am J Trop Med Hyg. 1995;53(5):489-506.

54. Saleeza SNR, Norma-Rashid Y, Sofian-Azirun M. Mosquitoes larval breeding habitat in urban and suburban areas, Peninsular Malaysia. Intern J Bioeng Life Sci. 2011;5(10):599-603.

55. Bi P, Zhang Y, Parton KA. Weather variables and Japanese encephalitis in the metropolitan area of Jinan city, China. J Infect. 2007;55(6):551-6.

56. Sripugdee $S$, Inmoung Y, Junggoth R. Impact of climate change on dengue hemorrhagic fever epidemics. Res J Appl Sci. 2010;5(4):260-2.

57. Rao BB, George B. Breeding patterns of Aedes stegomyia albopictus in periurban areas of Calicut, Kerala, India. Southeast Asian J Trop Med Public Health. 2010;41(3):536-40.

58. Thabiany Aziz A, Dieng H, Ahmad AH, Mahyoub JA, Turkistani AM, Mesed $\mathrm{H}$, et al. Household survey of container-breeding mosquitoes and climatic factors influencing the prevalence of Aedes aegypti (Diptera: Culicidae) in Makkah City, Saudi Arabia. Doc Head Asian Pac J Trop Biomed. 2012;2(11):849-57.

59. Mattah PAD, Futagbi G, Amekudzi LK, Mattah MM, De Souza DK, KarteyAttipoe WD, et al. Diversity in breeding sites and distribution of Anopheles mosquitoes in selected urban areas of southern Ghana. Parasites Vectors. 2017;10(1):1-15.

60. De Silva PM, Marshall JM. Factors contributing to urban malaria transmission in sub-saharan Africa: a systematic review. J Trop Med. 2012;2012:819563.

61. Sinka ME, Pironon S, Massey NC, Longbottom J, Hemingway J, Moyes CL, et al. A new malaria vector in Africa: predicting the expansion range of Anopheles stephensi and identifying the urban populations at risk. Proc Natl Acad Sci USA. 2020;117(40):24900-8.

\section{Publisher's Note}

Springer Nature remains neutral with regard to jurisdictional claims in published maps and institutional affiliations.

Ready to submit your research? Choose BMC and benefit from

- fast, convenient online submission

- thorough peer review by experienced researchers in your field

- rapid publication on acceptance

- support for research data, including large and complex data types

- gold Open Access which fosters wider collaboration and increased citations

- maximum visibility for your research: over $100 \mathrm{M}$ website views per year

At BMC, research is always in progress.

Learn more biomedcentral.com/submissions 